\title{
Study of Liver and Kidney functions in non-pregnant, pregnant and preeclamptic women
}

\author{
Zainab G.Hussein*
}

Received 3, March, 2011

Accepted 14, June, 2011

\begin{abstract}
:
Three groups of subjects have been divided (25/group): healthy normotensive non-pregnant women (Group A), normal normotensive pregnant women (Group B), and women with preeclampsia (Group C).The levels of serum alanine aminotransferase (ALT), aspartate aminotransferase (AST), total bilirubin , creatinine, blood urea nitrogen, triglyceride, total cholesterol and glucose have been estimated in all subjects. All measured parameters were determined by spectrophotometric analysis. The results showed a significant $(\mathrm{P}<0.05)$ increase in serum ALT, AST, blood urea nitrogen, triglyceride and total cholesterol levels in group B as compared to group A. However creatinine, total bilirubin and glucose levels did not show any statistical significant alterations. The women in group $\mathrm{C}$ showed to be associated with a significant $(\mathrm{P}<0.05)$ rise in all measured parameters except total bilirubin as compared to women in group A.

The preeclamptic women (group $\mathrm{C}$ ) showed significant $(\mathrm{P}<0.05)$ increase in serum alanine aminotransferase, blood urea nitrogen, triglyceride, total cholesterol and glucose levels as compared to women in group B. While serum aspartate aminotransferase, total bilirubin and creatinine levels did not show any statistical significant alteration.
\end{abstract}

Key words: Preeclampsia, liver enzymes, creatinine, blood lipids

\section{Introduction:}

preeclampsia is an idiopathic multisystem disorder specific to pregnancy. It is characterized by hypertension (systolic blood pressure $\geq$ $140 \mathrm{mmHg}$ and diastolic blood pressure $\geq 90 \mathrm{mmHg}$ and protein urea after 20 weeks of gestation) [1,2]. Preeclampsia complicates about $6-8$ $\%$ of all pregnancies worldwide [3]. It is associated with increased maternal morbidity and mortality. The preeclamptic also associated with development of chronic hypertension, as well as cardiovascular and renal complications later in life [4]. Several etiologies have been implicated in the development of preeclampsia including abnormal trophoblastinvasion of uterine blood vessels and immunological intolerance between fetoplacental and maternal tissues [5]. Abnormal liver functions were seen in $10 \%$ of pregnancies although these change often do not represent liver diseases. High levels of serum aminotransferases or bilirubin in pregnant women are abnormal and should prompt a diagnostic work up [6].

Several studies have shown that women with preeclampsia have cardiovascular risk profiles in pregnancy associated with levels of serum lipids and blood pressure. It remains uncertain if these characteristics reflect primary causes of preeclampsia or if they are secondary markers of this disease. It is

* Department of Science / College of Basic Education / University of Al-Mustansiriah 
also uncertain whether the increased risk of cardiovascular diseases subsequent to preeclampsia is due to exposures during that pregnancy or due to underlying biological traits of the mother. It is important to identify women who are at high risk of developing the disease early in pregnancy. This is because early identification of biochemical markers of the disease would not only facilitate selective recruiting of those at increased risk for preeclampsia but also to help in determining those patients who were more likely to benefit from interventional measures should a therapeutic intervention prove successful[7.8,9].

The aims of this study were to study the association of hypertensive pregnancy disorders with modifiable risk factors for liver, renal and cardiovascular diseases and to estimate the feasibility for early detection and prevention.

\section{Materials and Methods:}

This study was performed in the Iben - Albaladie Hospital in Baghdad. Three groups of women (25 / group) have been selected for the study.

Group (A) Healthy normotensive nonpregnant women.

Group (B) Healthy normotensive pregnant women.

Group (C) women with preeclampsia

The age of the women was between $18-35$ years. All women of group (B) and (C) were in the third trimester of pregnancy. The preeclamptic women were diagnosed by the presence of persistent hypertension (more than or equal 140 / $90 \mathrm{mmHg}$ ), gross proteinuria (tested by heat test of urine) and pathological oedema. Blood samples have been drawn from all the subjects following a fast of 12 hours. The blood was transferred to a plain tubes allowed to stand at room temperature for 10 minutes to permit clot formation. After centrifugation for 15 minutes at 300 (r.p.m) the serum was taken for analysis.

\section{Estimation of biochemical parameters}

- Estimation of serum alanin aminotransferase and aspartate aminotransferase enzymes activity by colorimetric method [10].

- Estimation of serum total bilirubin [11].

- Estimation of serum creatinine [12].

- Estimation of urea in serum by Urease enzymatic colorimetric method [13].

- Estimation of serum triglyceride was done using human diagnostics kit by GOP-PAP method [14].

- Estimation of serum total cholesterol by using diagnostics manual kit by CHOD-PAP method [15].

- Estimation of serum glucose by Trinder method, this procedure for the measurement of Glucose employs a modification of the glucose / peroxidase (GOD-POD) [16].

The statistical analysis for this study was carried out by using the computer program (Microsoft Excel) and includes: Mean, Standard Deviation and T-test [17].

\section{Results and Discussion:}

The demographic and clinical parameters of the groups are summarized in Table (1). 
Table (1) Mean value for (age, gestational age , number of deliver, systolic BP and diastolic BP) in group $A, B$ and $C$

\begin{tabular}{|c|c|c|c|c|}
\hline & Group A & Group B & Group C & P-value \\
\hline $\begin{array}{c}\text { Age } \\
\text { (year) }\end{array}$ & $28.87 \pm 4.63$ & $28.00 \pm 4.12$ & $\begin{array}{c}29.44 \pm 5.2 \\
0\end{array}$ & $\mathrm{P}>0.05$ \\
\hline $\begin{array}{c}\text { Gestation } \\
\text { al Age } \\
\text { (weeks) }\end{array}$ & - & $36.43 \pm 0.77$ & $\begin{array}{c}36.86 \pm 0.8 \\
2\end{array}$ & $\mathrm{P}>0.05$ \\
\hline $\begin{array}{c}\text { Number } \\
\text { of deliver }\end{array}$ & $2.31 \pm 1.12$ & $2.00 \pm 1.60$ & $3.88 \pm 1.25$ & $\mathrm{P}<0.05$ \\
\hline $\begin{array}{c}\text { Systolic } \\
\text { BP(mmH } \\
\text { g) }\end{array}$ & $\begin{array}{c}109.27 \pm 8.0 \\
5\end{array}$ & $\begin{array}{c}110.21 \pm 7.5 \\
6\end{array}$ & $\begin{array}{c}160.75 \pm 12 \\
.46\end{array}$ & $\mathrm{P}<0.05$ \\
\hline $\begin{array}{c}\text { Diastolic } \\
\text { BP(mmH } \\
\mathrm{g} \text { ) }\end{array}$ & $71.92 \pm 5.11$ & $75.63 \pm 5.63$ & $\begin{array}{c}102.50 \pm 10 \\
.35\end{array}$ & $\mathrm{P}<0.05$ \\
\hline
\end{tabular}

The results showed that age and gestational age did not differ significantly between groups. Number of deliver was significantly different when compared the preeclamptic group (group C) with both normotensive pregnant women (group B) and healthy normotensive non pregnant women (group A). Mean systolic and diastolic blood pressure were significantly higher in group $\mathrm{C}$ as compared to group B and C.

The results in table (2) showed that a serum ALT level was significantly increased in both normotensive pregnant women (group B) and preeclamptic women (group C) as compared to normotensive non pregnant women (group A). There was significant different in serum ALT levels between preeclamptic and normotensive pregnant women. This study is in agreement with many other studies [18, 19, 20, 21].

Serum AST levels were significantly increased in both group B and group $\mathrm{C}$ as compared to group $\mathrm{A}$. But there was no significant difference in serum AST levels between preeclamptic and normotensive pregnant women. This study is in agreement with other studies $[18,19,20,22]$. The preeclampsia was the common cause of raised ALT and AST levels during the third trimester of pregnancy [23].
The pathogenesis' of preeclampsia appears to occur in two phases: abnormal implantation of the placenta leading to impaired placental blood flow, which in turn include the release of pathogenic factors in the maternal circulation results in endothelial injury in many maternal organs especially the liver and kidney. Liver biopsies of patients with preeclampsia showed fibrin deposition in the periportal sinusoids and hepatocellular necrosis[24] .The alanine aminotransferase and aspartate aminotransferase are intracellular enzyme involved in amino acid and carbohydrate metabolism, they are elevated (as showed in table 2) may be due to organic damage which cells are rich in enzymes (may be the liver) [25]. Total Bilirubin levels were found to be similar in three groups. There were no significant differences between the groups, which is in agreement with other studies $[18,26]$.

Serum creatinine levels in (group B) showed no significant differences as compared to ( group A ), while the levels of creatinine in ( group C) were significantly increased as compared to group A, There was also no significant difference between preeclamptic and normotensive pregnant women. These results were seen by other investigator [27] who found that no significant difference in the mean values of creatinine in preeclamptic and normotensive pregnant women. This was contrary to the findings of other works which showed that serum creatinine levels were usually raised in patients destined to develop preeclampsia [18, 21] However the inclusion criteria used in some of these studies were slightly different from those of the present study, For instance some of the studies include patients with mixed parity (nulliparous and multiparous women) some with 
chronic hypertension and renal disease [28].

Blood urea nitrogen was significantly increased in (group B) as compared to (group A), The levels of blood urea nitrogen were increased significantly in (group C) as compared to (group A), Also the results from this study showed significantly difference in blood urea nitrogen in (group C)as compared to (group B), The results from this study were in agreement with other studies[18, 21] In preeclampsia renal perfusion and glomerular filtration are markedly reduced secondary to renal dysfunction, While the definite cause of renal dysfunction in preeclampsia remains unclear, one possible mechanism might be damage caused by endothelin, a potent endogenous vasoconstrictor peptide produced by endothelial cells[29].

Some previous studies showed that most dramatic damage in the lipid profile in normal pregnancy was serum hypertriglyceridemia, which may be as high as two to three folds in the third trimester over the levels in nonpregnant women [30]. In our study serum triglyceride levels showed significant increase in (group B) and (group C) as compared to (group A), There were also significant increase in serum triglyceride levels in preeclamptic women as compared to normotensive pregnant women. These results were in agreement with other studies found that the principle modulator of hypertriglyceridemia is estrogen as pregnancy is associated with hyperestrogenemia, estrogen includes hepatic biosynthesis of endogenous triglyceride. This process may be modulated by hyperinsulinism found in pregnancy[31,32].
Serum

triglyceride concentration also highly significantly rose in preeclampsia. This is due to increased endothelial triglyceride accumulation may result in endothelial cell dysfunction ingestosis[33]. In this study the rise in serum total cholesterol was statistically significant in all groups. Increased total cholesterol found in pregnancy induced hypertension is likely to be deposited in predisposed vessels such as the uterine spiral arteries and contributes to the endothelial dysfunction [34].

Fasting glucose levels were similar in (group A) and (group B). Other investigators have came up with same results [35]. But there were significant increased in serum glucose levels in (group C) as compared to (group A). But this increased within the normal range of fasting glucose in serum. The results also showed no significant difference in serum glucose levels between (group C) and (group $\mathrm{B})$, which is in agreement with other study [36].

$$
\text { Healthy pregnancies were }
$$
typically characterized by insulin resistance compared with the nonpregnant state, including up regulation of maternal carbohydrate and lipid metabolism. These adaptive responses to pregnancy meet demands of the rapidly developing fetus [8] and in preeclamptic pregnancies these metabolic up regulations seen to be exaggerated compared with uncomplicated pregnancies [37]. Therefor the excessive metabolic changes of preeclamptic pregnancies may be regarded as a stress test for maternal cardiovascular function [38]. 
Table (2) Mean serum value for ( ALT, AST, total bilirubin , creatinine, blood urea nitrogen, triglyceride, total cholesterol and glucose) in group $A, B$ and $C$.

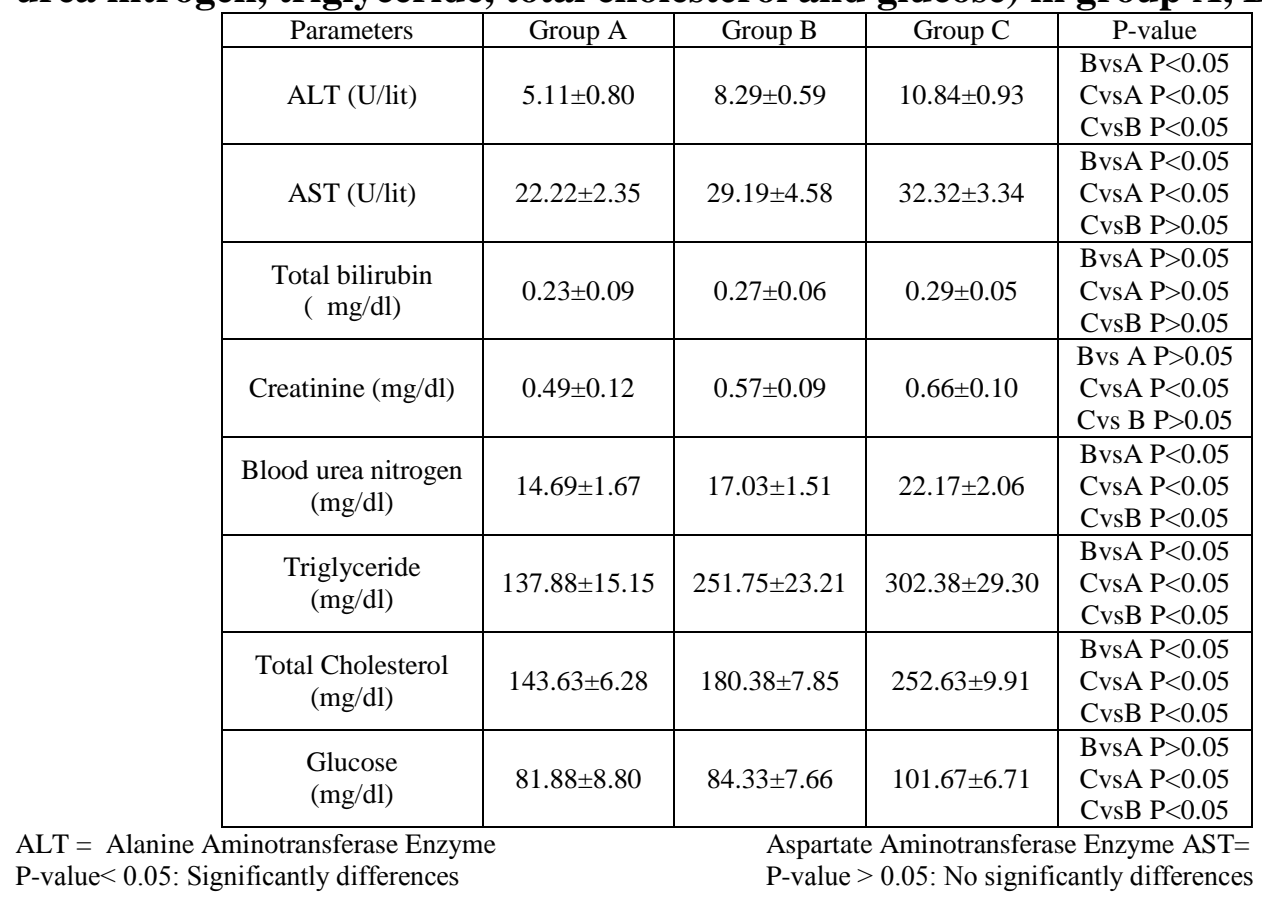

The pathogenesis of
preeclampsia is uncertain but
predisposition dysfunction is thought to play a crucial part [39]. Risk factors for preeclampsia such as chronic hypertension, liver disease, renal disease and diabetes are all conditions where endothelial dysfunction is a common feature [37] further more unfavorable lipid levels are associated with endothelial dysfunction and may precede the development of atheromatous disease [7].

As a conclusion preeclampsia is a multisystem disorder, characterized by vascular endothelial dysfunction. In our study the higher levels of all measured parameters in preeclamptic pregnancies are very useful markers to identify the occurrence of the complications of preeclampsia in early pregnancy which may reduced the risk of occurrence of disease.

\section{References:}

1. Wagner, L.K.2004.Diagnosis and Management of preeclampsia, American Family Physician. 70(12):2318-2324.

2. Prakash, J.; Pandey, L.K.; Singh, A.K. and Kar, B. 2006. Hypertension in pregnancy, Hospital based study, JAPI. 54:273278.

3. Norwitz, E.R.1999. Preventation of Preeclampsia: is it possible, Clinical obstetrics and gynecology. 42:446454.

4. Sibai, B.M. and Gonzalez, R.A.1986.Severe preeclampsia eclampsia in young primigravid women: subsequent pregnancy outcome and remote prognosis, Am Journal Obestet Gynaecol. 155:1011-6.

5. James, D.K.; Steer, P. J.; Weiner, C.P. and Gonik, B. 2005.High risk pregnancy management option. Philadelphia, WB Saunders, $3^{\text {rd }}$ ed., pp 352.

6. Fleming, J.W. and Zein, N.N.2005. The liver in pregnancy disease vs 
benign changes, Cleveland Clinical Journal of Medicine. 72(8)731-721.

7. Magnussen, E.B.; Vatten, L.J. ; Nilsen, T.L. and Salvesen, K.A. 2007. Pregnancy cardiovascular risk factors as predictors of preeclampsia: population based Cohort study. BMJ.355:966-978.

8. Rodie, V.A.; Freeman, D.J. and Sattar, N.G.2004.Preeclampsia and cardiovascular disease: metabolic syndrome of pregnancy. Atherosclerosis. 175:189-202.

9. Ray, J.G.; Diamond, P. ; Singh, G. and Bell, C.M. 2006. Brief overview of maternal triglycerides as a risk factor for preeclampsia, Br.J. Obstet. Gynacol.113: 379-38.

10. Reitman, S. and Frankel, S. 1957. A colorimetric method for determination of serum glutamic osaloacetic and glutamic - pyruvic transaminases, Am. J. Clin. Pathol. 28:56-61

11. Shull, B.C. and Less, H.1980. Mechanism of interference by hemoglobin in the determination of total Bilirubin. Method of Jendrassif Grof, Clin.Chem.26 (1):22-25.

12. Bonsnes, R.W. and Taussky, H.A. 1945. The colorimetric determination of creatinine by Jaff reaction, J. Biol. Chem. 158:581591.

13. Fawcett, J.K. and Scott, J.E.1960. A rapid and precise method for the determination of urea, Clin. Path. 13:156-159.

14. Werner, M.; Gabrielson, D.G. and Eastman, G.1981. Ultra micro determination of serum triglycerides by bioluminescent assay, Clin. Chem. 27:268-271.

15. Allain, C.C.; Poon, L.S. and Chan, C.SG. $1974 . \quad$ Enzymatic determination of total serum cholesterol, Clin.Chem.20:470-475.

16. Trinder, P.1969. Determination of glucose in blood using glucose oxidase with an alternative oxygen acceptor, Ann.Clin.Biochem.6:2428.

17. Knusel, L.1998. On the accuracy of statistical distributions in Microsoft excel 97, Comput. Statist. Data. Anal.26:375-377.

18. Mirzaie, F.; Shorbaf, F.R. and Kazeronie, A.H. 2009.Association of maternal C - reactive protein levels with severity of preeclampsia, Acta Medical Iranica. 47 (4):293296.

19. Ziaei, S.; Ranjkesh, F. and Faghihzadeh, S.2008. Evaluation of 24 hours urine copper in preeclamptic vs. normotensive pregnant and non pregnant women, International J.Fert.Ster.2 (1):9-12.

20. Slowinsk i,T. ; Neumayer, H.H. ; Stolze, T. ; Gossing, G. ; Halle, H. and Houcher, B. 2002. Endothelin system in normal and hypertensive pregnancy, Clinical Science.103 (48):446S-449S.

21. Saylik, S.A. ; Alkis, I. ; Bayram, N. ; Tuna, V. ; Imamoglu, N. and Ceylan ,Y. 2009. Maternal serum leptin levels in severe preeclamptic pregnant women in early postpartum stage, International Journal of Medicine and Medical Sciences. 1(6):248- 253.

22. Bayhan, G.; Atamer, Y. and Atamer, A.2000. Significance of changes in lipid peroxides and antioxidant enzyme activities in pregnant women with preeclampsia and eclampsia , Clin Expobstet Gynecol. 27(2):142-146.

23. Wong, H.Y. ; Tan, J.Y. and Lim, C.C.2004. Abnormal liver functions testes in the symptomatic pregnant patient: The local Experiences in Singapore, Annals Academy of Medicine. 33 (2):204-208.

24. Malarewicz, A. ; Gruszka, O. ; Szymkiewicz, J. and Rogala, J. 2006. The usefulness of routine laboratory tests in the evaluation of 
sudden threat of pregnant women and fetus in preeclampsia, Ginekol Pol.77 (4):276-284.

25. Demir, S.C. ; Evruke, C. ; Ozgunen , F.T. ; Urunsak, I.F. ; Candan, E. and Kaday, O. 2006. Factors that influence morbidity in sever preeclampsia, eclampsia and hemolysis elevated liver enzymes and low platelet count syndrome , Saudi Med.J.27 (7):1015-1018.

26. Salako, B.L. ; Odukogbe, A.T. ; Olayemi, O. ; Adedapo, K.S. ; Aimakhu, C.O. and Alu, F.F. 2003. Serum Albumin, Creatinine and uric acid and hypertensive disorders of pregnancy, East Afric.Med.J. 80(8):424-428.

27. Conde, A.; Belizan, J.M.; Lede, R. and Bergel, E.F. 1993. What does an elevated mean arterial pressure in the second half of pregnancy predict Gestational hypertension or preeclampsiam , Am. J. Obstet.Gynaecol.169:509-514.

28. Clark, A.B. 1992. Plasma endothelin levels and renal impairment, Am. J .Obstet. Gynecol. 166:962-968.

29. Chiang, A.N. ; Yang, M.L. ; Hung, J.H. ; Chan , P. and Shyn, S.K. 1995. Alteration of serum lipids levels and their biological relevance during and after pregnancy, Life Sci.56 (26):2367-2375.

30. Jayanta, D. ; Mukhopadhyay, A.K. and Saha, P.K. 2006. Study of serum lipids profile in pregnancy induced hypertension, Indian Journal of Clinical Biochemistry. 21 (2):165-168.

31. Glueck, C.J. ; Fallet, R.W. and Scheel, D. 1975. Effects of Oestrogenic compounds on triglyceride kinetics, Metabolism. 24:537-545.

32. Adegoke, O.A. ; Lyare, E.E. and Gbenebitse, S.O. 2003. Fasting plasma glucose and cholesterol levels in pregnant Nigerian women, Niger.Post grad.Med.J.10 (1):32-36.

33. Mikhail, M.S. ; Basu, J. ; Palan, P.R. ; Furgiusle, J.; Rommey, S.L. and Anyaegbunam, A. 1995 . Lipid profile in women with preeclampsia: relationship between plasma triglyceride levels and severity of preeclampsia, J.Assoc. Acad. Minorphys. 6(1):43-45.

34. Sattar, N. ; Bendomir, A. ; Berry, C. ; Shepherd, J. ; Greer, I.A. and Packard, C.J. 1997. Lipoprotein sub fraction concentrations in preeclampsia: Pathogenic parallels to atherosclerosis, Obstet. Gynecol. 89(3):403-408.

35. Innes, K.E. ; Wimsatt, J.H. and Mcduffie, R. 2001. Relative glucose tolerance and subsequent development of hypertension in pregnancy, Obstet. Gynecol.97:905910.

36. Khosravi, S.M. and Kaboudi, B. 2004. Insulin changes in preeclamptic women during pregnancy, Ann. Saudi. Med.24 (6):434-436.

37. Sibai, B.; Dekker, G. and Kupferminc, M. 2005. Preeclampsia, Lacent. 365:785-799.

38. Sattar, N and Greer, I.A. 2002. Pregnancy complications and maternal cardiovascular risk, B.M.J.325:157-160.

39. Redman, C.W.; Sacks, G.P. and Sargent, I.L. 1999. Preeclampsia: an excessive maternal inflammatory response to pregnancy, Am. J. Obstet. Gynecol.180:499-506. 


\title{
دراسة وظائف الكبد والكلى عند النساء غير الحوامل و الحوامل والحوامل المصابات بتسمم الحمل العل
}

\section{زينب غالب حسين*}

\author{
*قسم العلوم / كلية التربية الاساسية / الجامعة المستنصرية
}

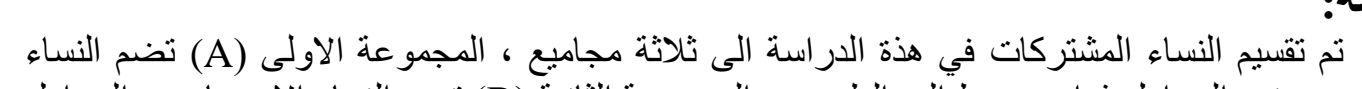

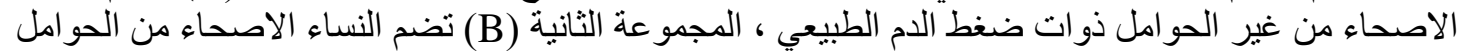

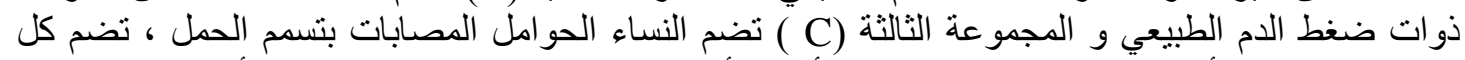

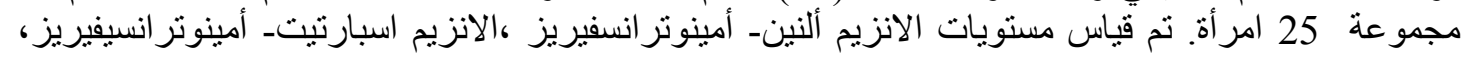

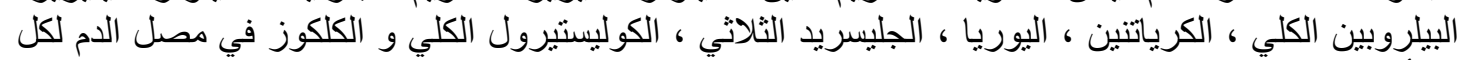

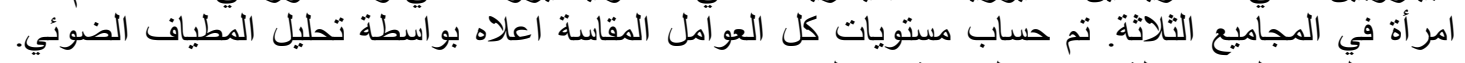

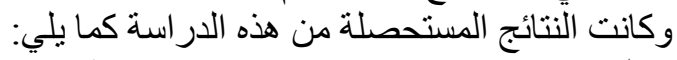

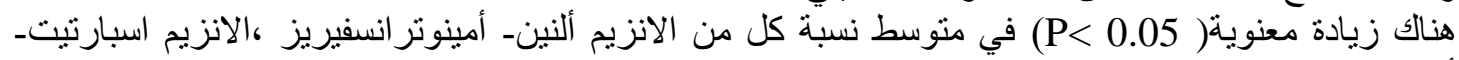

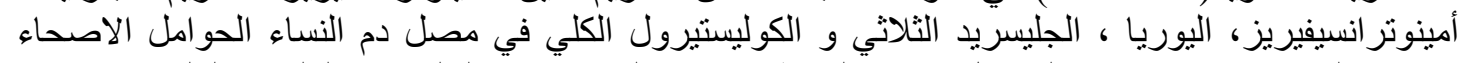

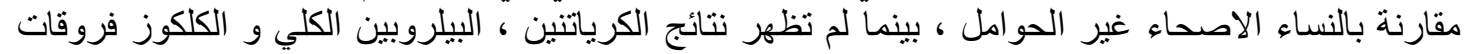

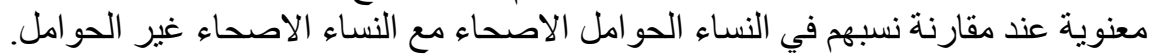

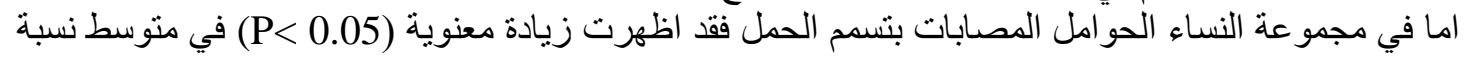

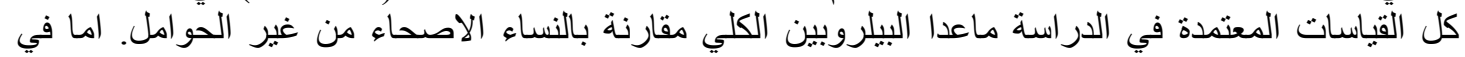

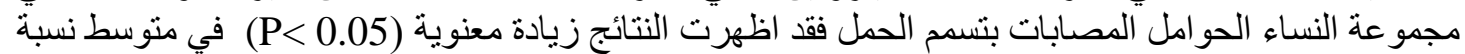

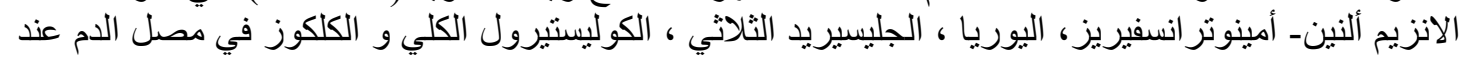

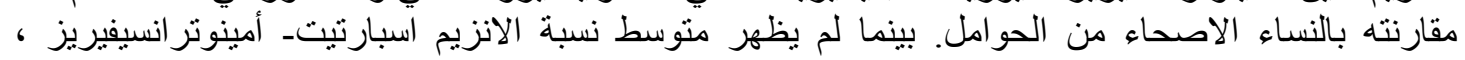

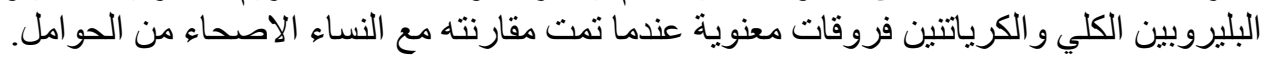

